\title{
Interaction of Intraluminal Tissue and Coronary Sinus Lead Stabilized with Stent Placement
}

\author{
TIBOR BALÁZS, M.Sc., * BÉLA MERKELY, Ph.D.,† ESZTER BOGNÁR, M.Sc., Ph.D., \\ and ENDRE ZIMA, PH.D. $\dagger$
}

From the *Department of Materials Science and Engineering, Budapest University of Technology and Economics, Budapest, Bertalan Lajos 7. MT, Hungary; and †Heart Center, Semmelweis University, Budapest, Városmajor 68, Hungary

Intraluminal Interaction of Tissue and Stented CS Lead. Introduction: The aim of our investigation was to examine the intraluminal interaction of the vascular tissue and the implanted coronary sinus lead stabilized with stent on two human hearts removed before transplantation.

Methods and results: The coronary sinus lumen was sectioned under operational microscope and opened carefully. The leads and stents were found separately positioned beside each other completely covered by an intact intimal tissue layer. No sign of occluding proliferative tissue was observed.

Conclusion: Stent fixation technique and extraction of the CS lead in our cases did not have any particular damaging effect on the vascular system. (J Cardiovasc Electrophysiol, Vol. pp. 1-3)

cardiac resynchronization therapy, coronary sinus lead, implantable cardioverter defibrillator, stent

\section{Introduction}

Cardiac resynchronization therapy (CRT) is an effective nonpharmacological therapeutic method for the treatment of selected patients with chronic heart failure associated with wide QRS complex and mechanical dyssynchrony. Implantation of the coronary sinus (CS) lead is still the technically most challenging part of CRT, 5-9\% of patients have dislodgement or microdislodgements during the follow-up, resulting in loss of resynchronization or inadvertent phrenic nerve stimulation. ${ }^{1-4}$ The recently published MADIT CRT trial showed that $7.5 \%$ of CS lead implantations were unsuccessful ${ }^{5}$ and $5-10 \%$ of patients required re-operation during the follow-up because of CS lead dysfunction. ${ }^{5-7}$ Stent implantation may increase the stability of the lead position by anchoring the CS electrode to the wall of the CS side branch. A stable lead position may improve the implantation success rate and decrease postoperative complications. ${ }^{8,9}$

The aim of our study was to examine the intraluminal tissue reaction of coronary sinus induced by an implanted CS lead, stabilized with a coronary stent on two surgically removed hearts. The morphological vascular alterations of the coronary sinus and the effects of the extraction of implanted devices on the blood vessels were also investigated.

This work was supported by grants from the National Development Agency of Hungary (TÁMOP-4.2.2-08/1/KMR-2008-0004 "Semmelweis Híd Projekt") and Hungarian Research Fund (grant NKTH-OTKA K68792).

\section{No disclosures.}

Address for correspondence: Tibor Balázs, M.Sc., Department of Materials Science and Engineering, Budapest University of Technology and Economics, H-1111 Budapest, Bertalan Lajos 7. MT, Hungary. Fax: +36-1326-4945; E-mail: balazs.tibor@freemail.hu

Manuscript received 5 January 2011; De novo manuscript received 9 August 2012; Accepted for publication 10 August 2012.

doi: 10.1111/j.1540-8167.2012.02447.x
Methods

\section{Clinical Background}

Patient No. 1 was a 58-year-old woman with a history of serious chronic heart failure due to dilated cardiomyopathy with left bundle branch block (native QRS width during atrial fibrillation: $130 \mathrm{~ms}$ ). A CRT-P and later an upgraded CRT-D system implantations were performed to improve the progressively worsening functional cardiac state. Patient No. 2 was a 58-year-old man with a history of progressive chronic heart failure due to dilated cardiomyopathy with left bundle branch block (QRS width: $170 \mathrm{~ms}$ ). The patient underwent CRT-D implantation because of a documented nonsustained ventricular tachycardia.

Both of the patients responded initially to CRT therapy and then the clinical course was led by the continuous worsening of the heart failure. They were scheduled to heart transplantation formerly and the ICD backup was the choice of bridge to transplant.

The coronary sinus leads were positioned into a lateral side branch of CS. In both cases intraoperative dislodgement occurred due to the unstable anatomical position of the CS leads (Patient 1: Corox OTW UP 75, Biotronik; Patient 2: Attain OTW 4193, Medtronic). Stent placement was used to achieve effective pacing from the CS site and to prevent lead dislodgement: a second guide wire was introduced into the target vein over the same CS sheath, then the coronary stent was positioned over this second guide wire introduced into the CS side branch besides the lead body. The CS leads were successfully stabilized with properly deployed coronary stents (Patient 1: Micro Driver 2.5×8, Medtronic; Patient 2: Trimaxx $3.0 \times 11$, Abbott Vascular). Stents were deployed with a pressure of 10 atmospheres with a duration of $6 \mathrm{sec}$ onds. The diameter of the stents was chosen according to the diameter of the target CS side branch which was measured on the CS venogram. Measurements after expanding the stent showed appropriate left ventricular pacing parameters that remained stable during the observation.

The leads functioned for 26 months (Patient 1) and 15 months (Patient 2) after implantation, when the patients 


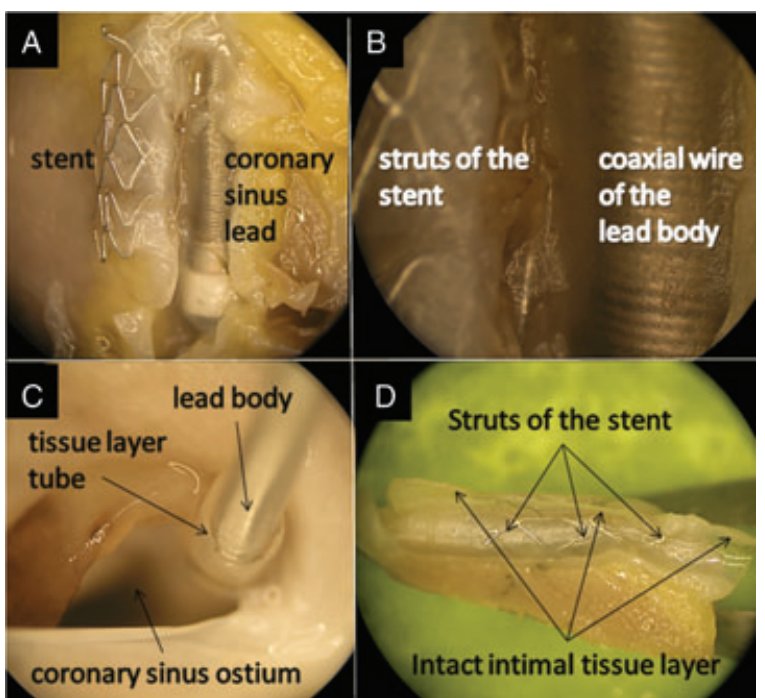

Figure 1. Endothelial tissue proliferation around the coronary sinus lead stabilized with a stent. A: Microscopic view after dissection of the vein, the stent and the lead are positioned separately. B: Magnified image of distance between the lead body and coronary stent after dissection of the vein. $C$ : The lead covered with a thin tissue layer beyond the coronary ostium. D: The cross-sectional view of the tissue tube after the lead extraction, the struts of the stent are covered with a tissue layer.

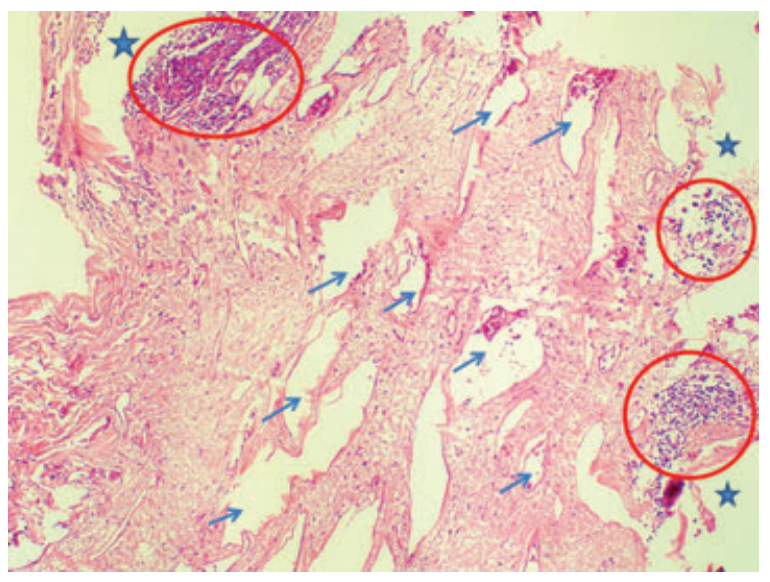

Figure 2. Recanalization within the stent lumen (Blue stars: details of the location of removed stent struts. Red circles: the area of chronic inflammaory cells [mainly lymphocytes] in foci located in the vicinity of the stent struts. Blue arrows: recanalization within the stent lumen, cellular blood components [RBC and WBC] in the lumen of small vessels).

underwent successful heart transplantation due to worsening heart failure. The heart was removed together with the lead stabilized by the stent and it was immersed in a formalin solution for fixation and further morphological examination.

\section{Method of Investigation}

The coronary sinus was dissected and opened along its long axis with extraordinary care to protect the delicate structure of the CS and implanted devices. Stereo Microscope (Nikon, SMZ2T) and Olympus Camedia 5500 digital camera were used to record the procedure. After the removal of the covering tissue layer, the CS lead and stent positions were recorded. Under visual microscopic control the CS leads

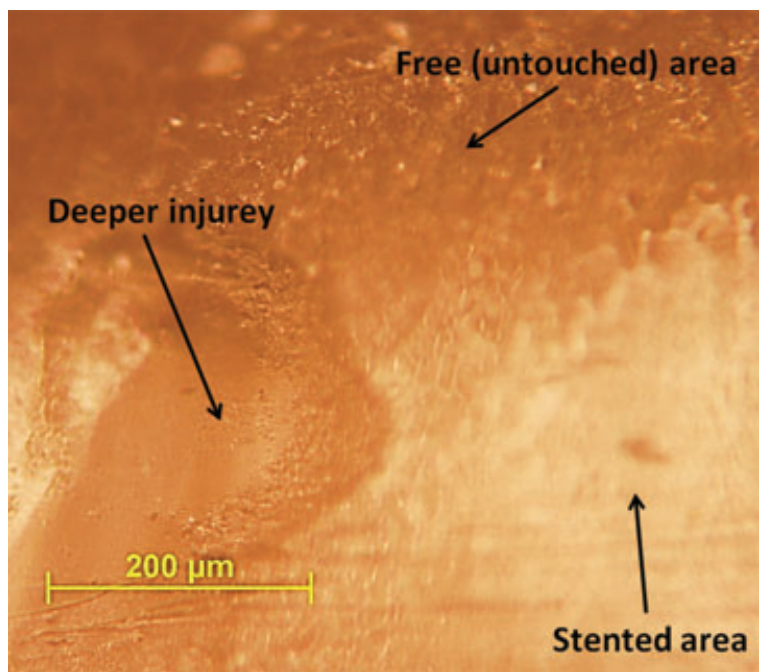

Figure 3. Damages of the explanted coronary sinus lead stabilized with a stent. The deepest injury is visible as well as the stented area, which is smooth, the free surface is rugged.

were manually extracted. Optical analysis was used to further examine the stents and coronary sinus after extraction.

A coronary sinus section was prepared for histological examination hematoxylin-eosin staining under Zeiss microscope and the pictures were recorded by a digital camera.

The analysis of coronary sinus lead surface, detection of insulation damages and verification of electronic and functional integrity with microscopy and impedance measurement were performed using previously published methodology. ${ }^{10,11}$

\section{Results}

The coronary sinus leads and stents were completely covered with an intact intimal tissue layer. In both cases the lead and the stent was found separately positioned besides each other, without any morphological sign of proliferative or scarring tissue reaction (Fig. 1). The thickness of the tissue layer between the lead and the stent was $370 \mu \mathrm{m}$ at the lead body and it was $110 \mu \mathrm{m}$ at the tip area in Patient 1 . The tissue layer in Patient 2 was $96 \mu \mathrm{m}$ thick between the lead and the coronary stent.

The coronary sinus leads were gently and easily extracted manually without any particular physical effort. During the removal procedure of these 2 cases neither stent deformation nor any noticeable tissue damage was observed in the coronary sinus. The tissue reaction formed a tube-like coverage around the lead that was intact after the gentle extraction and no injury was found on the inner surface of the tissue layer.

Histological examination (Fig. 2) of the coronary sinus confirmed recanalization of the coronary stent lumen. Accumulation of chronic inflammatory cells (mainly lymphocytes) was visible in the internal lumen of coronary stent. Recanalization was recognized with formation of small vessels and cellular blood components (RBC and WBC).

The results of impedance measurements of the explanted did not show measurable electronic leakage during the insulation testing.

Only one deeper injury (Fig. 3) was detected on the surface of the Corox OTW lead, close to the tip, where the stent was placed. The surface damage had a dimension of 279 (width) 
$\times 250$ (length) $\times 34$ (depth) $\mu \mathrm{m}$, which did not penetrate the thickness of the insulation. Minor, 3-5 $\mu \mathrm{m}$ deep, superficial surface injuries were found on the Attain OTW lead in the stented area. No injury was observed that might have resulted from the lead extraction.

\section{Discussion}

Pacemaker electrode stabilization with coronary stent placement can be a useful technique to maintain an optimal and stable position of implanted coronary sinus lead to prevent dislodgements or microdislodgements. ${ }^{12-15}$

In our case reports we examined the intraluminal physical and histological changes around the lead and the stent in the coronary sinus. We assume that the deeper damage and minor surface injuries at the stented region might be the result of the continuous friction due to the heart motion but not related to the lead extraction. The tissue layer in between the stent and the lead probably prevented injuries during extraction. Based on our findings it is not possible to determine how much the implantation process did contribute to the changes observed at the end of a long follow-up.

In our cases, the stent fixation technique did not have any particular damaging effect on the local vascular system. The images show an excellent internal protecting tissue layer with tube formation around the lead. The stent is rather deeply impacted into the inner vascular wall covered with a tissue layer. No traces of active thrombotic process, developing scars, tissue proliferation or chronic total occlusion were found. We could not reveal total lumen loss in the affected coronary sinus region that might be the result of some maintained blood flow through the implanted stent after the implantation. The histological examination proved evidence of endothelization process that likely is a complex tissue regenerating procedure as the result of a delicate interaction of blood components and vessel wall.

Mechanical support of stent for the fixation of lead is probably beneficial in the early postinterventional period until the intravascular endothelial reaction is completed, developing a tube-like tissue structure that keeps the lead in position. However, these observations are based only on the examination of two samples, therefore, further studies and in situ observations are required for a better understanding of the lead-stent-vessel intravascular interaction.

Acknowledgments: The authors wish to thank to Prof. Dr. Miklós Tekeres for his valuable advice and for the preliminary proof-reading.

\section{References}

1. McAlister FA, Ezekowitz JA, Wiebe N, Rowe B, Spooner C, Crumley E, Hartling L, Klassen T, Abraham W: Systematic review: Cardiac resyn- chronization in patients with symptomatic heart failure. Ann Internal Med. 2004;141:381-390.

2. Cleland JG, Daubert JC, Erdmann E, Freemantle N, Gras D, Kappenberger L, Tavazzi L: Cardiac resynchronization-heart failure (CARE-HF) investigators: The effect of cardiac resynchronization on morbidity and mortality in heart failure. N Engl J Med 2005;352:15391549.

3. Strickberger SA, Conti J, Daoud EG, Havranek E, Mehra MR, Piña IL, Young J; Heart Rhythm Society: Patient selection for cardiac resynchronization therapy: From the Council on Clinical Cardiology Subcommittee on Electrocardiography and Arrhythmias and the Quality of Care and Outcomes Research Interdisciplinary Working Group in collaboration with the Heart Rhythm Society. Circulation 2005;11:21462150.

4. Koos R, Sinha AM, Markus K, Breithardt OA, Mischke K, Zarse M, Schmid M, Autschbach R, Hanrath P, Stellbrink C: Comparison of left ventricular lead placement via the coronary venous approach versus lateral thoracotomy in patients receiving cardiac resynchronization therapy. Am J Cardiol 2004;94:59-63.

5. Moss AJ, Hall WJ, Cannom DS, Klein H, Brown MW, Daubert JP, Estes M, Foster E, Greenberg H, Higgins SL, Pfeffer MA, Solomon SD, Wilber D, Zareba W: Cardiac resynchronization therapy for the prevention of heart failure events. N Engl J Med 2009;361:13291338.

6. Gras D, Bocker D, Lunati M, Wellens HJJ, Calvert M, Freemantle N, Gervais R, Kappenberger L, Tavazzi L, Erdmann E, Cleland JGF, Daubert JC: Implantation of cardiac resynchronization therapy systems in the CARE HF trial: Procedural success rate and safety. Europace 2007;9:516-522.

7. Leon AR, Abraham WT, Curtis AB, Daubert JP, Fisher WG, Gurley J, Hayes DL, Lieberman R, Petersen-Stejskal S, Wheelan K: Safety of transvenous cardiac resynchronization system implantation in patients with chronic heart failure: Combined results of over 2,000 patients from a multicenter study program. J Am Coll Cardiol 2005;46:23482356.

8. Kowalski O, Prokopczuk J, Lenarczyk R, Pruszkowska-Skrzep P, Poloński L, Kalarus Z: Coronary sinus stenting for the stabilization of left ventricular lead during resynchronization therapy. Europace 2006;8:367-370.

9. Ermis C, Benditt DG: Stent-stabilization of left ventricular pacing leads for cardiac resynchronization therapy: A promising concept? J Cardivasc Electrophysiol 2007;18:308-309.

10. Laczkó R, Balázs T, Bognár E, Ginsztler J: Injuries of previously stent stabilized left ventricular pacemaker lead during simulated lead extraction, 9th YSESM, 2010; ISBN 978-88-95940-30-4. 235.

11. Balázs T, Merkely B, Bognár E, Gellér L, Szilágyi S, Dobranszky J, Zima E: Methods for examination an explanted left ventricular pacemaker lead stabilized with a coronary stent. Pacing Clin Electrophysiol 2010; doi: 10.1111/j.1540-8159.2010.02955.x.

12. Gellér L, Szilágyi Sz, Róka A, Merkely B: Coronary sinus side branch stenting as a tool for coronary sinus lead dislocation in patients with heart failure and left bundle branch block. Eur Heart J 2005;26(Suppl 1):52/P486

13. Cesario DA, Shenoda M, Brar R, Shivkumar K: Left ventricular lead stabilization utilizing a coronary stent. Pac Clin Electrophysiol 2006;29:427-428.

14. Szilagyi S, Merkely B, Roka A, Zima E, Fulop G, Kutyifa V, Szucs G, Becker D, Apor A, Geller L: Stabilization of the coronary sinus electrode position with coronary stent implantation to prevent and treat dislocation. J Cardiovasc Electrophysiol 2007;18:303-307.

15. Gellér L, Szilágyi S, Zima E, Molnár L, Széplaki G, Végh EM, Osztheimer I, Merkely B: Long-term experience with coronary sinus side branch stenting to stabilize left ventricular electrode position. Heart Rhythm 2011;8:845-850. 